\title{
Evidence for direct action of alloxan to induce insulin resistance at the cellular level
}

\author{
M. Ader, J.M. Richey, R. N. Bergman
}

University of Southern California School of Medicine, Department of Physiology and Biophysics, Los Angeles, California, USA

\begin{abstract}
Summary To determine whether long-term insulin deficiency alters insulin movement across the endothelium, plasma and lymph dynamics were assessed in dogs after alloxan $(50 \mathrm{mg} / \mathrm{kg} ; n=8)$ or saline injection $(n=6)$. Glucose tolerance $\left(\mathrm{K}_{\mathrm{G}}\right)$ and acute insulin response were assessed by glucose injection before and 18 days after treatment. Two days later, hyperglycae$\mathrm{mic}(16.7 \mathrm{mmol} / \mathrm{l})$ hyperinsulinaemic $\left(60 \mathrm{pmol} \cdot \mathrm{min}^{-1}\right.$. $\mathrm{kg}^{-1}$ ) glucose clamps were carried out in a subset of dogs ( $n=5$ for each group), with simultaneous sampling of arterial blood and hindlimb lymph. Alloxan induced fasting hyperglycaemia $(12.9 \pm 2.3$ vs $5.7 \pm$ $0.2 \mathrm{mmol} / \mathrm{l} ; p=0.018$ vs pre-treatment) and variable insulinopenia (62 \pm 14 vs $107 \pm 19 \mathrm{pmol} / \mathrm{l} ; p=0.079)$. The acute insulin response, however, was suppressed by alloxan (integrated insulin from 0-10 min: $155 \pm$ 113 vs $\left.2745 \pm 541 \mathrm{pmol} \cdot \mathrm{l}^{-1} \cdot 10 \mathrm{~min}^{-1} ; p=0.0027\right)$, resulting in pronounced glucose intolerance $\left(\mathrm{K}_{\mathrm{G}}: 0.99 \pm\right.$ 0.19 vs $3.14 \pm 0.38 \mathrm{~min}^{-1} ; p=0.0002$ vs dogs treated with saline). During clamps, steady state arterial insulin was higher in dogs treated with alloxan $(688 \pm 60$ vs $502 \pm 38 \mathrm{pmol} / 1 ; p=0.023)$ due to a $25 \%$ reduction
\end{abstract}

Received: 3 November 1997 and in final revised form: 2 June 1998

Corresponding author: M. Ader, Ph. D., University of Southern California School of Medicine, Department of Physiology and Biophysics, MMR 624, 1333 San Pablo St., Los Angeles, CA 90033, USA

Abbreviations: Glucose tolerance, $\mathrm{K}_{\mathrm{G}}$; glucose uptake, $\mathrm{R}_{\mathrm{d}}$; transendothelial transport, TET; coefficient of variation, CV; glucose-stimulated insulin release, $\mathrm{AIR}_{\mathrm{g}}$; hepatic glucose output, $\mathrm{HGO}$; whole body insulin sensitivity, $\mathrm{S}_{\mathrm{I}(\mathrm{clamp})}$; halftimes, $t_{1 / 2}$. in insulin clearance $(p=0.045)$. Lymph insulin concentrations were also raised $(361 \pm 15$ vs $266 \pm$ $27 \mathrm{pmol} / \mathrm{l} ; p=0.023$ ), such that the lymph to arterial ratio was unchanged by alloxan $(0.539 \pm 0.022$ vs $0.533 \pm 0.033 ; p=0.87)$. Despite higher lymph insulin, glucose uptake $\left(\mathrm{R}_{\mathrm{d}}\right)$ was significantly diminished after injection of alloxan $(45.4 \pm 2.5$ vs $64.3 \pm 6.5 \mu \mathrm{mol}$. $\left.\mathrm{min}^{-1} \cdot \mathrm{kg}^{-1} ; p=0.042\right)$. This was reflected in resistance of target tissues to the lymph insulin signal $\left(\Delta \mathrm{R}_{\mathrm{d}}\right)$ $\Delta$ lymph insulin: $3.389 \pm 1.093$ vs $11.635 \pm 2.057 \cdot 10^{-6}$. $\left.1 \cdot \min ^{-1} \cdot \mathrm{kg}^{-1} \cdot \mathrm{pmol}^{-1} \cdot \mathrm{l}^{-1} ; p=0.012\right)$ which correlated strongly with the $\mathrm{K}_{\mathrm{G}}(r=0.86 ; p=0.0001)$. In conclusion, alloxan induces insulinopenic diabetes, with glucose intolerance and insulin resistance at the target tissue level. Alloxan treatment, however, does not alter lymph insulin kinetics, indicating that insulin resistance of Type 1 (insulin-dependent) diabetes mellitus reflects direct impairment at the cellular level. [Diabetologia (1998) 41: 1327-1336]

Keywords Insulin transport, experimental diabetes, insulin action
Type I (insulin-dependent) diabetes mellitus is characterized by fasting hyperglycaemia, insulinopenia, and profound glucose intolerance. Impaired insulinmediated glucose uptake has also been reported in both Type I diabetes $[1,2]$ as well as insulin-deficient diabetic animal models [3, 4], with the severity of resistance directly related to degree of hyperglycaemia. This resistance reflects defects in insulin-stimulated glucose transport due to impaired recruitment of glucose transporter GLUT4 to the plasma membrane [5], although the defect is reversed when insulin or phlorizin return fasting hyperglycaemia to normal [6, 7]. Alternatively, it has been suggested that reduced 
blood flow to skeletal muscle could explain the decreased uptake into insulin-sensitive tissues [8].

We have shown that the capillary endothelial barrier is a critical factor of insulin's action to accelerate glucose utilization, such that transendothelial transport (TET) of insulin has a major role in determining the time course of insulin action in vivo $[9,10]$. Although plasma and interstitial insulin kinetics are not impaired in obesity-related insulin resistance [11, 12], there are several reasons to propose that defects in this step can contribute to resistance of diabetes. Most importantly, diabetic microangiopathy is a common complication of poorly controlled Type I diabetes and is characterized by thickening of the capillary basement membrane, impaired vasodilatory response to nitric oxide, and altered permeability to fluorescein dyes and macromolecules such as albumin which greatly exceed the size of insulin [13]. Furthermore, it has been reported that capillary endothelial cells of streptozotocin-diabetic rats exhibit defects in autophosphorylation and action of insulin receptors [14], which could cause altered TET, if insulin transport was receptor-mediated [15], although this has not been shown in vivo [16]. Thus, it is possible that alterations in TET could contribute to the insulin resistance of insulin deficient diabetes.

To examine whether peripheral insulin resistance of insulin-deficient diabetes is caused by altered movement of insulin between vascular compartments, we did experiments to assess plasma and interstitial insulin dynamics and action in dogs treated with alloxan. We quantified the degree of alloxan-induced metabolic dysfunction and glucose intolerance by glucose injection before and after treatment. Dogs were then studied by glucose clamps in which plasma and hindlimb lymph fluid were sampled and glucose turnover assessed, to quantify lymph insulin dynamics and both whole body and tissue sensitivity in alloxan diabetes.

\section{Materials and methods}

Animals. Experiments were done on 14 male mongrel dogs $(18.2-28.6 \mathrm{~kg})$. Animals were housed in the University of Southern California vivarium under controlled kennel conditions (12 h light, $12 \mathrm{~h}$ dark) and fed standard chow ( $25 \%$ protein, $9 \%$ fat, and $49 \%$ carbohydrate: Wayne Dog Chow, Alfred Mills, Chicago, Ill., USA) once daily. Body temperature and weight were monitored regularly. Dogs were used for experiments only if judged healthy by general appearance and the above measurements.

Animals were randomly assigned to a diabetic $(n=8)$ or control $(n=6)$ group. Diabetes was induced by single intravenous injection of alloxan monohydrate $(50 \mathrm{mg} / \mathrm{kg})$, followed by saline flush. Insulin treatment was initiated 2 days after injection, and consisted of a 1:2 mixture of Regular and NPH purified pork insulin (Novo-Nordisk, Copenhagen, Denmark) once a day to maintain glycosuria below $1 \%$. Dogs treated with this insulin regimen do not develop insulin antibodies for at least 2 months [17]. Dogs in the control group received intravenous saline instead of alloxan. All procedures were approved by the USC Institutional Animal Care and Use Committee.

Experimental design. Dogs had up to three experimental procedures: a glucose injection before and 18-20 days after alloxan or saline injection, and a hyperinsulinaemic glucose clamp with sampling of lymphatic fluid. Clamps were done on a subset of animals from each group ( $n=5$ each). Glucose injection procedures were carried out in conscious animals surgically prepared with an indwelling catheter in the jugular vein with the tip advanced into the right atrium for injection and sampling. On the day of the hyperglycaemic clamp, a second surgery was done. Clamps were done at least $1 \mathrm{~h}$ following completion of surgery to implant catheters in the carotid artery and hindlimb lymphatic vessel. Because of the difficulty to maintain intact and patent hindlimb catheters in conscious dogs, all clamp procedures were carried out on dogs anaesthetized with halothane. After the clamp experiments the animals were killed by pentobarbital overdose.

Surgical preparation. At least 7 days before the first experiment, surgery was done as described previously [18] to implant an indwelling catheter in the jugular vein with the tip advanced into the right atrium for sampling of central venous blood and injection of glucose and insulin during glucose injection.

The morning of the clamp experiment, two additional indwelling catheters for sampling of arterial blood and lymph from a hindlimb lymph vessel were implanted. After an overnight fast, dogs were preanaesthetized with acepromazine maleate (Prom-Ace, Aueco, Fort Dodge, Iowa, USA) and atropine sulphate (H.Schein, Port Washington, N. Y., USA). Anaesthesia was induced with sodium thiamylal (Biotal, Bioceutic Labs, St. Joseph, Mo., USA) and maintained with halothane and nitrous oxide. Following vertical incision above the trachea, a catheter was inserted into left common carotid artery for blood sampling. A longitudinal incision was then made in the left hindlimb distal to the femoral triangle, and hindlimb lymphatics were exposed. After identification of a sufficiently large lymphatic vessel, a polyaethylene catheter (PE-50, inner diametre $0.58 \mathrm{~mm}$, outer diametre $0.965 \mathrm{~mm}$ ) was threaded through a pinhole, advanced past at least one lymph valve ( $\sim 1$ to $2 \mathrm{~cm}$ beyond the insertion point) and secured in place with silk sutures. Body temperature was maintained with a warming pad and heart rate and blood pressure were monitored continuously throughout the surgical and experimental procedures. After successful implantation of all indwelling catheters, a hyperinsulinaemic hyperglycaemic clamp experiment was carried out as described below.

Experimental protocols. A total of 28 glucose injection protocols were done. Each dog was studied twice: before and 1820 days after alloxan or saline injection. During experiments dogs were conscious, rested comfortably in a Pavlov sling, and had free access to water. After an overnight fast, 3 basal blood samples $(3 \mathrm{ml})$ were collected at time $-20,-10$, and $-1 \mathrm{~min}$. At time 0 , glucose $(0.3 \mathrm{~g} / \mathrm{kg})$ was injected over $30 \mathrm{~s}$ via the right atrial catheter and samples drawn at 2, 3, 4, and 5 min, every $2 \mathrm{~min}$ from 6 to $12 \mathrm{~min}$, and at 15, 17, and $19 \mathrm{~min}$. A total of 14 blood samples were drawn during the glucose injection protocol.

A total of 10 hyperinsulinaemic hyperglycaemic clamps were done in a subgroup of dogs treated with alloxan and saline ( $n=5$ for each group). After implantation of indwelling catheters in the carotid artery and hindlimb lymphatic vessel, intravenous catheters were placed in the left saphenous vein for 
infusion of porcine insulin, in the left cephalic vein for infusion of glucose, and in the right cephalic vein for infusion of tracer $\left(\left[3-{ }^{3} \mathrm{H}\right]\right.$-glucose $)$ to assess glucose turnover. Exogenous glucose was labelled with a trace quantity of $\left[3-{ }^{3} \mathrm{H}\right]$-glucose to avoid rapid dilution of the labelled glucose pool with unlabelled glucose [19]. The specific activity of exogenously infused glucose was calculated to compensate for predicted changes in hepatic glucose output (HGO) during hyperinsulinaemic hyperglycaemia using the following equation [20]:

$\mathrm{SA}_{\mathrm{G}}=\frac{\mathrm{SA}_{\mathrm{P}} \times(\mathrm{HGO}+\mathrm{GINF})-\mathrm{I}^{*}}{\mathrm{GINF}}$

where $\mathrm{SA}_{\mathrm{G}}$ and $\mathrm{SA}_{\mathrm{P}}$ are glucose specific activity in glucose infusate and plasma, respectively (in dpm/mg), and I* represents tracer infusion rate (in $\mathrm{dpm} / \mathrm{min}$ ). $\mathrm{HGO}$ and glucose infusion rate $(\mathrm{GINF})$, in $\mathrm{mg} / \mathrm{min}$, represent steady state values which would be expected at the levels of hyperglycaemia and hyperinsulinaemia used in this study.

At $-180 \mathrm{~min}$, a tracer infusion of $3-{ }^{3} \mathrm{H}$-glucose $(0.25 \mu \mathrm{Ci} /$ min) was started. After the 120 -min tracer equilibration period, 7 basal blood and lymph samples were collected every $10 \mathrm{~min}$ from time -60 to $-10 \mathrm{~min}$, and at $-1 \mathrm{~min}$. Beginning at time zero, and continuing for $240 \mathrm{~min}$ infusions of porcine insulin $\left(60 \mathrm{pmol} \cdot \mathrm{min}^{-1} \cdot \mathrm{kg}^{-1}\right)$ and somatostatin $(0.8 \mu \mathrm{g}$. $\left.\min ^{-1} \cdot \mathrm{kg}^{-1}\right)$ were started. Hyperglycaemia was achieved by intravenous glucose injection $(0.3 \mathrm{~g} / \mathrm{kg})$ at time 0 , followed by variable rate infusion of $50 \%$ dextrose to maintain arterial glucose at $16.7 \mathrm{mmol} / \mathrm{l}$. Glucose was not injected in animals with fasting hyperglycaemia of more than $11.1 \mathrm{mmol} / \mathrm{l}(n=2$ animals treated with alloxan). Arterial blood samples were taken every min from 1-9 min, every 5 min between 10 and $25 \mathrm{~min}$, and every $10 \mathrm{~min}$ until $240 \mathrm{~min}$. Hindlimb lymph samples were taken every $5 \mathrm{~min}$ between 0 and $25 \mathrm{~min}$ and every $10 \mathrm{~min}$ between 30 and $240 \mathrm{~min}$. A total of 42 blood and 34 lymph samples were collected. Urine was collected to correct for glycosuria.

Blood and lymph sampling. Blood (4 ml) and hindlimb lymph $(\sim 1.0 \mathrm{ml})$ samples were collected in tubes containing heparin and $\mathrm{NaF}$ and stored on ice until centrifugation. After separation all samples were stored at $-20^{\circ} \mathrm{C}$ until assayed for insulin, glucose, and ${ }^{3} \mathrm{H}$-glucose specific activity.

Sampling of hindlimb lymph was collected during continuous massage of the limb over a period of $5 \mathrm{~min}$, starting $2.5 \mathrm{~min}$ before and ending $2.5 \mathrm{~min}$ after the blood sampling. In all experiments, at least $400 \mu \mathrm{l}$ of hindlimb lymph was obtained at each sampling; thus the flow rate averaged at least $0.08 \mathrm{ml} / \mathrm{min}$.

Assays. Plasma and lymph glucose were assayed in duplicate by the glucose oxidase technique on an automated analyser (YSI, Model 23A, Yellow Spring Instruments, Yellow Springs, Ohio, USA). Intra-assay coefficient of variation $(\mathrm{CV})$ of the glucose assay was $1.3 \pm 0.1 \%$. Insulin in plasma and lymph was measured in duplicate by the highly specific sandwich ELISA method [21], which does not crossreact with proinsulin. The ELISA uses two monoclonal antibodies which bind to distinct epitopes on the insulin molecule; antibody HUI-018 binds to the A-chain, and antibody OXI-005 targets the C-terminus of the B-chain. The limit of detection in the ELISA is $5 \mathrm{pmol} / \mathrm{l}$, with intraassay $\mathrm{CV}=4.0 \pm 0.3 \%$.

To determine $\left[3-{ }^{3} \mathrm{H}\right]$-glucose in plasma and lymph, samples were deproteinized with $\mathrm{Zn}_{2} \mathrm{SO}_{4}$ and $\mathrm{BaOH}_{2}$. The supernatant was then dried at $70^{\circ} \mathrm{C}$, re-dissolved in water, and counted in ReadySafe scintillation fluid (Beckman Fullerton, Calif., USA) on a Beckman liquid scintillation counter with a 2-chan- nel dual-label automatic-quench correction programme. Plasma and lymph samples from each experiment were measured in the same assay.

Materials. Alloxan monohydrate and porcine insulin (for infusion) were purchased from Sigma (St. Louis, Mo., USA). Insulin for treatment of diabetic dogs (Regular and NPH; purified pork) was obtained from Novo-Nordisk. Dextrose (50\%) was acquired from Kendall McGaw (Irvine, Calif., USA). Cyclic somatostatin was from Bachem (Torrance, Calif., USA). Tritiated glucose was obtained from Amersham (Arlington, Ill., USA).

Data analysis and calculations. Fasting glucose and insulin were determined as the mean of three basal values obtained before glucose injection. Glucose tolerance $\left(\mathrm{K}_{\mathrm{G}}\right)$ was calculated as the negative slope of the natural log of glucose versus time from 10 to $19 \mathrm{~min}$ [22]. Glucose-stimulated insulin release $\left(\mathrm{AIR}_{\mathrm{g}}\right)$ was calculated as the integrated plasma insulin response above basal from 0 to $10 \mathrm{~min}$.

Tracer-determined whole body $\mathrm{R}_{\mathrm{d}}$ and endogenous $\mathrm{HGO}$ were calculated according to Finegood et al. [19] after smoothing plasma glucose and tracer data by optimal segments [23] as modified by Bradley [24]. Steady state was defined as the final hour of the hyperglycaemic clamp (180 to $240 \mathrm{~min}$ ). Half time $\left(t_{1 / 2}\right)$ for appearance of insulin in plasma and lymph was defined as the time when $50 \%$ of the increment from basal to steady state was attained, and was calculated from smoothed data.

Whole body insulin sensitivity $\left(\mathrm{S}_{\mathrm{I}(\mathrm{clamp})}\right)$, representing the combined effects of hyperinsulinaemia on liver and periphery, was calculated as the ratio of glucose infusion rate to incremental plasma insulin at steady state, divided by prevailing glucose (to estimate the effect of hyperglycaemia on $R_{d}$, see Discussion section). Similarly, the component of insulin sensitivity which only quantifies insulin's actions to stimulate glucose utilization $\left(\mathrm{S}_{\mathrm{IP}(\mathrm{clamp})}\right)$ was calculated as the ratio of the incremental increase in $R_{d}$ to the incremental increase in plasma insulin, divided by steady state glucose [25]. This variable was found to be independent of prevailing glucose [26].

The steady state lymph to plasma insulin ratio was calculated by dividing steady-state lymph insulin concentrations by the respective arterial plasma insulin concentration. Insulin concentration gradients were sometimes present during the basal period, therefore insulin concentrations were corrected for basal in order to compare lymph to plasma ratios due solely to infused insulin.

Insulin sensitivity measures which are based on lymph rather than plasma insulin are a measure of insulin's action on insulin-sensitive cells. Since lymph insulin reflects hormone actually presented to insulin-sensitive tissues, lymph-based measures reflect the ability of the insulin signal to stimulate measures glucose uptake. In other words, plasma-based measures of insulin sensitivity describe combined actions of insulin to traverse the endothelial barrier and bind to and stimulate the intracellular cascade within insulin-sensitive tissues. Lymphbased sensitivity reflects binding and action of the insulin signal only, thus describing tissue insulin sensitivity alone.

Statistical analysis. All statistics ( $t$-tests and analysis of variance (ANOVA)) were done using MINITAB statistical software (MINITAB Inc.; State College, Pa., USA). Data are reported as means \pm SEM. Statistical significance was set at $p$ less than 0.05 . 

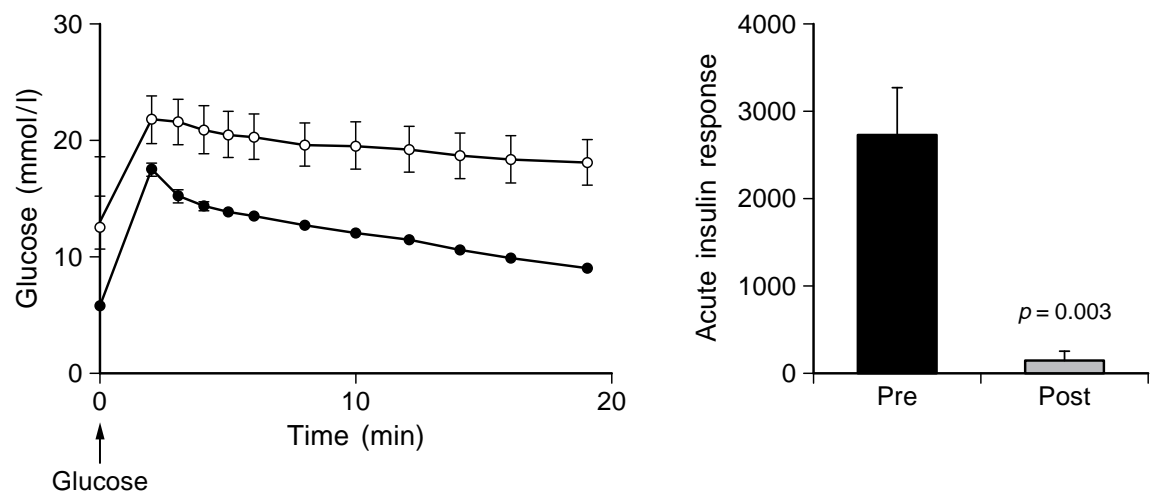

Fig. 1. Effect of alloxan treatment on glucose tolerance and acute insulin response. - - - , pre-alloxan; - $\bigcirc-$, post-alloxan
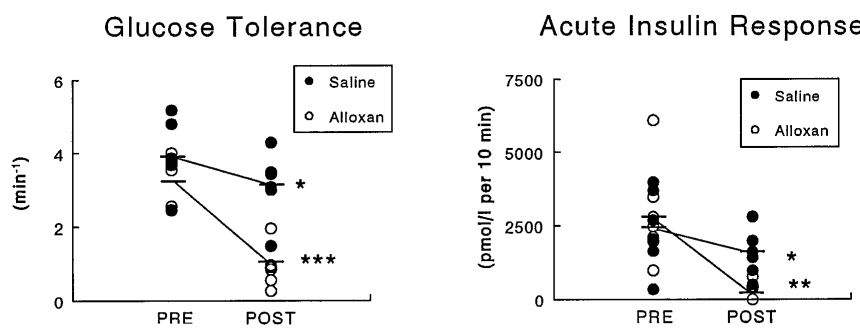

Fig. 2. Glucose tolerance and acute insulin response in individual dogs before and after saline or alloxan treatment. Symbols represent individual dogs. Horizontal lines represent mean values. Statistics reflect comparisons between pre- and post-values

\section{Results}

Fasting values. There was no change in fasting glucose or insulin in animals treated with saline. Alloxan induced fasting hyperglycaemia, as measured in conscious dogs $(12.9 \pm 2.3$ vs $5.7 \pm 0.2 \mathrm{mmol} / 1) ; p=$ 0.018 ), although this effect was variable (range: 6.0 to $21.4 \mathrm{mmol} / \mathrm{l}$ ). Mean fasting insulin was only modestly, but not significantly, reduced by alloxan injection $(62 \pm 14$ vs $107 \pm 19 \mathrm{pmol} / \mathrm{l} ; p=0.079)$. The fasting insulin, however, was near normal during hyperglycaemia, indicating a beta-cell defect.

\section{Glucose injection results}

Alloxan treatment. The effects of alloxan on glucose tolerance and insulin secretion are shown in Figure 1. Before alloxan treatment, plasma glucose declined rapidly after glucose injection. After alloxan injection, hyperglycaemia was evident in the basal state, and after glucose injection, glucose disappearance was prominently slower, as quantified by a diabetic level of glucose intolerance $\left(\mathrm{K}_{\mathrm{G}}: 0.99 \pm 0.19\right.$ vs $3.30 \pm$ $0.24 \mathrm{~min}^{-1}$ pre-alloxan; $p=0.0002$; Fig. 1 ).

Alloxan caused the expected alterations in glucose-stimulated insulin dynamics (Fig. 1). The AIR was reduced $92 \pm 4 \%$ for all dogs treated with alloxan, compared with pre-alloxan IVGTTs $(155 \pm 113$ vs $\left.2745 \pm 541 \mathrm{pmol} \cdot \mathrm{l}^{-1} \cdot 10 \mathrm{~min}^{-1} ; p=0.0027\right)$. Of the 5 animals exhibiting fasting hyperglycaemia, $\mathrm{AIR}_{\mathrm{g}}$ was completely eliminated in all cases; the remaining 3 animals who failed to develop hyperglycaemia also showed a severe $78 \pm 4 \%$ impairment in $\mathrm{AIR}_{\mathrm{g}}$.

Saline treatment. Control animals were tested before and 18-20 days after saline injection to examine the stability of metabolic variables during this period, and provide a control for any metabolic changes which may occur during the interval between experiments (Fig. 2). We observed a small $(20 \pm 6 \%$ ), but consistent drop in glucose tolerance during this observation period (3.14 \pm 0.38 vs pre-saline $\mathrm{K}_{\mathrm{G}}: 3.92 \pm 0.40 \mathrm{~min}^{-1}$; $p=0.022$ ). This was associated with a $23 \%$ decline in $\operatorname{AIR}_{\mathrm{g}}(p=0.026)$, observed in 5 of 6 animals.

\section{Glucose clamp results}

Clamp stability. Hyperinsulinaemic hyperglycaemic clamps were done with glucose targeted to $16.7 \mathrm{mmol} / \mathrm{l}$ (Fig.3). Target hyperglycaemia was achieved in both animals treated with alloxan on with saline $(16.7 \pm 0.1$ and $16.6 \pm 0.1 \mathrm{mmol} / \mathrm{l}$, respectively) and was stable during steady state (CV: $4 \pm 1$ and $3 \pm 1 \%$, respectively). Exogenously infused glucose was spiked with labelled glucose, therefore plasma specific activity remained reasonably stable during the clamp (CV over final hour: $5 \pm 1$ and $8 \pm 1 \%$ for animals treated with saline or with alloxan), although there was a tendency to increase over the entire experimental period (Fig. 3). Glucose infusions rates were significantly lower in dogs treated with alloxan $(p=0.0093$; Table 1$)$, indicating insulin resistance. Resistance also existed in the subgroup of animals treated with alloxan with near near-normal fasting glucose $\left(45.5 \pm 3.1\right.$ vs $39.7 \pm 3.9 \mu \mathrm{mol} \cdot \mathrm{min}^{-1}$. $\mathrm{kg}^{-1}$ for subset vs group treated with saline; $p=0.037)$.

Insulin concentrations. During insulin infusion in control animals, plasma hormone concentration in- 



Fig.3. Dynamics of glucose, plasma specific activity, and glucose infusion rates during hyperglycaemic hyperinsulinaemic glucose clamps. - - , saline; $-\mathrm{O}-$, alloxan

creased rapidly from a basal of $32 \pm 9$ to 502 \pm 38 pmol/l (Fig. 4). Lymph insulin concentrations were slightly, but not significantly lower than plasma at basal $(13 \pm 4 \mathrm{pmol} / \mathrm{l})$, but rose to a steady state concentration which was only $53 \pm 2 \%$ of plasma concentrations $(266 \pm 27 \mathrm{pmol} / \mathrm{l} ; p=0.0001)$.

In dogs treated with alloxan, there was a tendency for basal plasma insulin to be lower than in control animals $(10 \pm 5$ vs $32 \pm 9 \mathrm{pmol} / \mathrm{l} ; p=0.063)$. With insulin infusion, plasma insulin rose rapidly to $688 \pm$ $60 \mathrm{pmol} / 1,37 \%$ higher than in animals treated with saline. Thus, animals treated with alloxan showed reduced insulin clearance $(0.091 \pm 0.010$ vs $0.122 \pm$ $\left.0.0091 \cdot \mathrm{min}^{-1} \cdot \mathrm{kg}^{-1} ; p=0.045\right)$. Basal insulin concentrations in hindlimb lymph were $8 \pm 2 \mathrm{pmol} / \mathrm{l}$ (detection limit of ELISA: $5 \mathrm{pmol} / \mathrm{l}$ ), and increased to a steady state concentration lower than plasma (361 \pm $15 \mathrm{pmol} / \mathrm{l} ; p=0.023)$.

Insulin dynamics. In animals treated with saline dynamics of plasma insulin were noticeably faster than those of hindlimb lymph insulin $\left(\mathrm{t}_{1 / 2}: 4.8 \pm 1.6 \mathrm{vs}\right.$ $42.4 \pm 3.4 \mathrm{~min} ; p=0.0003$ ) and were similar to those we reported previously [27]. This difference in dynamics was also observed in animals treated with alloxan $\left(\mathrm{t}_{1 / 2}: 6.0 \pm 1.7\right.$ vs $\left.44.4 \pm 11.2 \mathrm{~min} ; p=0.0031\right)$. There was no difference in plasma or lymph insulin dynamics between animals treated with saline and with alloxan ( $p=0.62$ and $p=0.28$, respectively).

Insulin concentration gradients. Although higher plasma insulin concentrations were observed at steady state in animals treated with alloxan, hindlimb lymph insulin concentrations were proportionally increased (Fig. 5). Thus, the lymph:plasma insulin ratio at steady state (Fig. 5) was not different between alloxan and saline groups $(0.539 \pm 0.022$ vs $0.533 \pm$ $0.033 ; p=0.87)$, and was similar to concentration gradients calculated in earlier studies $(0.476 ;[27])$.

Glucose turnover. Mean basal glucose turnover was slightly, but not significantly higher overall in dogs treated with alloxan compared with control animals treated with saline $(p=0.32)$, although the two animals treated with alloxan which had fasting hyperglycaemia greater than $13.9 \mathrm{mmol} / \mathrm{l}$ had basal turnover rates that were 1.8-fold greater than those with relatively normal fasting glycaemia $(37.7 \pm 4.2$ vs $16.4 \pm$ $2.2 \mu \mathrm{mol} \cdot \mathrm{min}^{-1} \cdot \mathrm{kg}^{-1}$ ).

Despite higher insulin concentration in both plasma and lymph and matched hyperglycaemia, glucose utilization was significantly lower in animals treated with alloxan than in control animals treated with saline at steady state $(p=0.042)$. Glucose production was equally suppressed in both groups (Table 1).

Table 1. Glucose turnover during hyperglycaemic hyperinsulinaemic glucose clamps in dogs treated with alloxan or control animals treated with saline

\begin{tabular}{|c|c|c|c|c|c|c|}
\hline & \multicolumn{2}{|c|}{ GINF $^{\mathrm{a}}$} & \multicolumn{2}{|l|}{$\mathrm{HGO}$} & \multicolumn{2}{|l|}{$\mathrm{R}_{\mathrm{d}}$} \\
\hline & Basal & SS & Basal & SS & Basal & SS \\
\hline Alloxan & - & $39.7 \pm 3.9$ & $24.9 \pm 5.5$ & $6.2 \pm 3.6$ & $24.9 \pm 5.5$ & $45.4 \pm 2.5$ \\
\hline Saline & - & $59.9 \pm 4.1$ & $18.4 \pm 1.4$ & $4.1 \pm 5.9$ & $18.4 \pm 1.4$ & $64.3 \pm 6.5$ \\
\hline
\end{tabular}

${ }^{\mathrm{a}}$ Units: $\mu \mathrm{mol} \cdot \mathrm{min}^{-1} \cdot \mathrm{kg}^{-1}$ 


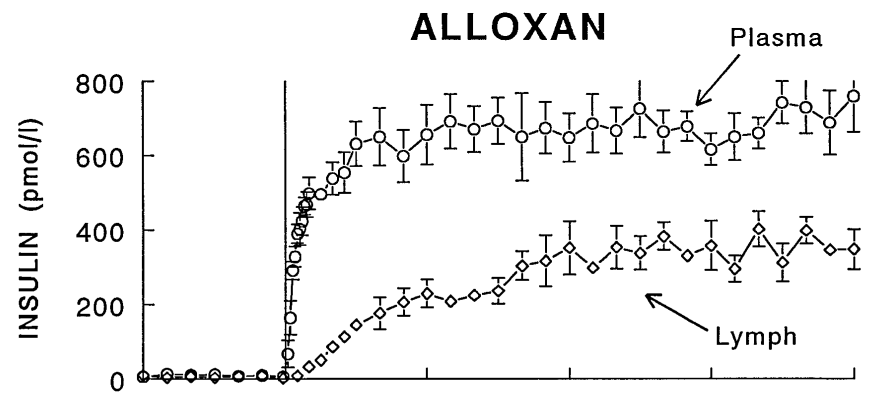

\section{SALINE}



Fig.4. Insulin dynamics from clamps performed in animals treated with alloxan or saline

Insulin sensitivity. With the knowledge of glucose turnover and insulin concentrations in both plasma and lymph, it is possible to calculate whole-body insulin sensitivity to stimulate glucose uptake $S_{\text {Ip(clamp) }}$, which includes both insulin transport as well as the sensitivity of tissues alone ("cellular insulin action") (Table 2).

We observed a $56 \%$ reduction in whole body insulin sensitivity in animals treated with alloxan $(p=$ $0.017)$. This reflects a severe impairment of $S_{\mathrm{IP}(\mathrm{clamp})}$, which was only $27 \%$ of that observed in control animals, as well as a degree of hepatic resistance, which was indicated by similar degrees of HGO suppression despite higher insulin concentrations during the clamp in diabetic animals.

Cellular insulin action. Dogs treated with alloxan showed pronounced impairment in the sensitivity of target tissues to lymph insulin, as compared with control animals $(p=0.016$; Table 2$)$. This was most pronounced when we examined the ability of lymph insulin to stimulate $R_{d}$, which was reduced by $71 \%$ compared with control animals. This process was strongly associated with glucose tolerance from IVGTTs carried out several days before the clamp (Fig.6) in which the ability of lymph insulin to stimulate glucose uptake could account for nearly $74 \%$ of the variability in the $\mathrm{K}_{\mathrm{G}}$.

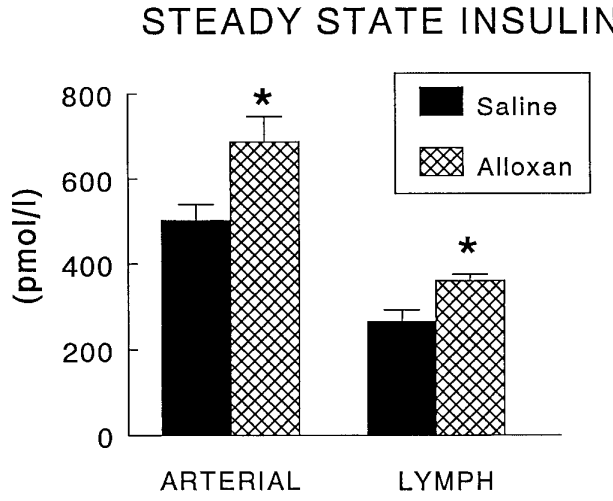

LYMPH:ARTERIAL INSULIN RATIO



Fig. 5. Steady state insulin and the lymph: arterial insulin gradient in animals treated with saline and with alloxan. $\mathbf{0}$, saline; , alloxan

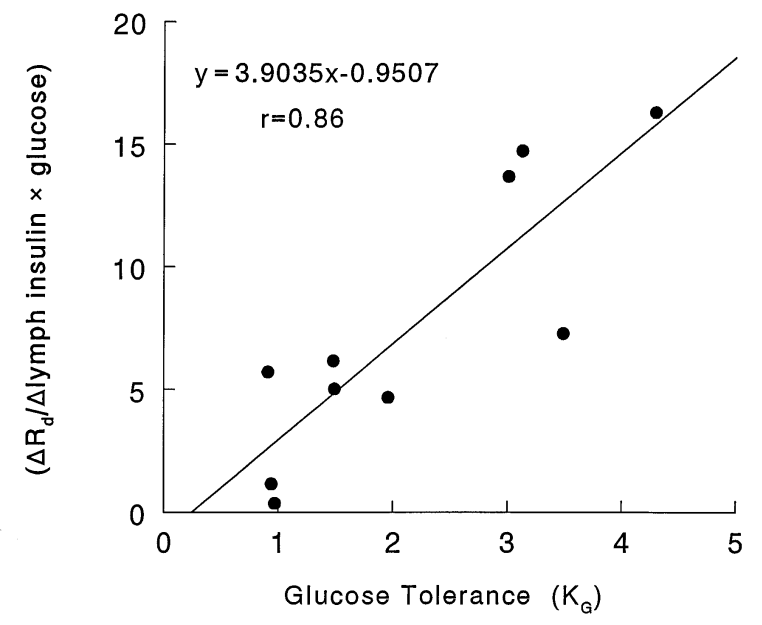

Fig. 6. Correlation between glucose tolerance and cellular insulin action $\left(\Delta \mathrm{R}_{\mathrm{d}} / \Delta\right.$ lymph insulin $\times$ glucose $)$, as determined from hyperglycaemic clamps. $\mathrm{y}=3.9035 \times-0.9507, r=0.86$

\section{Discussion}

Alloxan induced profound glucose intolerance because of the elimination of glucose-stimulated insulin secretion. Whole body insulin sensitivity and insulinstimulated glucose uptake were much lower in dogs treated with alloxan, compared with control animals. 
Table 2. Lymph : arterial gradient, insulin sensitivity and cellular insulin action from hyperglycaemic hyperinsulinaemic glucose clamps in dogs treated with alloxan or control animals treated with saline

\begin{tabular}{|c|c|c|c|c|c|}
\hline & \multirow{2}{*}{$\begin{array}{l}\text { Lymph: arterial } \\
\text { insulin ratio }\end{array}$} & \multicolumn{2}{|c|}{ Whole-body insulin sensitivity ${ }^{\mathrm{b}}$} & \multicolumn{2}{|c|}{ Cellular insulin action $^{c}$} \\
\hline & & $\overline{S_{I}}$ & $\mathrm{~S}_{\mathrm{IP}(\text { clamp) }}$ & $\mathrm{S}_{\mathrm{I}}$ & $\mathrm{S}_{\mathrm{IP}(\text { clamp) }}$ \\
\hline Alloxan & $0.533 \pm 0.033$ & $3.519 \pm 0.132$ & $1.670 \pm 0.500$ & $6.717 \pm 0.509$ & $3.389 \pm 1.093$ \\
\hline Saline & $0.539 \pm 0.022$ & $8.047 \pm 1.144$ & $6.232 \pm 1.075$ & $14.941 \pm 1.972$ & $11.635 \pm 2.057$ \\
\hline$p$-value ${ }^{\mathrm{d}}$ & 0.87 & 0.017 & 0.012 & 0.016 & 0.012 \\
\hline
\end{tabular}

${ }^{a}$ Lymph:plasma insulin ratio was calculated by dividing steady state lymph insulin concentration (above basal) by the respective arterial plasma concentration.

${ }^{\mathrm{b}}$ Whole body insulin sensitivity $\left(\mathrm{S}_{\mathrm{I}}, \mathrm{S}_{\mathrm{IP}}\right)$ was estimated from plasma insulin as the glucose infusion rate (for $\mathrm{S}_{\mathrm{I}}$ ) or $\Delta \mathrm{R}_{\mathrm{d}}$ (for $\mathrm{S}_{\mathrm{IP}}$ ) divided by the product of steady state plasma insulin (above basal) and glucose concentrations. Thus, $\mathrm{S}_{\mathrm{I}}$ reflects overall actions of insulin to stimulate $R_{d}$ and suppress $H G O$,

We observed that alloxan had no effect on insulin dynamics in interstitial fluid during clamps. Although insulin concentrations were higher in dogs treated with alloxan compared with control animals, both plasma and lymph concentrations were proportionally increased, such that concentration gradients between arterial plasma and hindlimb lymph were unchanged. Finally, glucose uptake was lower in the face of higher interstitial insulin indicating that treatment with alloxan induced severe insulin resistance at the target cell level.

The existence of insulin receptors on capillary endothelial cells which facilitate substrate metabolism of the endothelial cell itself has been reported [28]. An additional function was proposed in which insulin receptors mediated the unidirectional movement of insulin across an endothelial cell monolayer in vitro [15]. These receptors showed pronounced abnormalities in several rodent models of insulin-deficient diabetes (BB rat, streptozotocin-injected rat), suggesting that insulin transport in diabetes is impaired [14]. No alteration in interstitial insulin kinetics, however, could be detected from our studies in the dog [16].

This discrepancy may reflect species differences, since changes in distribution between plasma and interstitial compartments in the streptozotocin-diabetic rat have been reported [29]. Re-examination of this data, however, indicates that at the lowest level of hyperinsulinaemia studied $\left(438 \mathrm{pmol} \cdot \mathrm{min}^{-1} \cdot \mathrm{kg}^{-1}\right)$, the lymph:arterial insulin gradient was only slightly higher in diabetic rats ( 0.605 vs 0.574 in non-diabetic rats), and remarkably similar to that observed in the present study in dogs ( 0.533 and 0.539 for diabetic and non-diabetic animals, respectively). The failure to observe changes in interstitial insulin dynamics in diabetic dogs despite previous results [14], however, is also consistent with reports in our laboratory which indicate that in contrast to in vitro studies, insulin transport is not a receptor-mediated process in vivo [16]. Thus, defects in capillary endothelial insulin receptor function would not necessarily be reflected in whereas $S_{\text {IP }}$ quantifies only the actions on uptake. Units are $\times 10^{-6} \cdot 1 \cdot \mathrm{min}^{-1} \cdot \mathrm{kg}^{-1} \cdot \mathrm{pmol}^{-1} \cdot \mathrm{1}^{-1}$

${ }^{\mathrm{c}}$ Cellular insulin action is calculated similarly to whole body sensitivity, except that calculations are based on lymph insulin, rather than plasma insulin. Units are $\times 10^{-6} \cdot 1 \cdot \mathrm{min}^{-1} \cdot \mathrm{kg}^{-1}$. $\mathrm{pmol}^{-1} \cdot \mathrm{1}^{-1}$

${ }^{\mathrm{d}} p$-values: alloxan vs saline groups.

altered interstitial insulin dynamics or lymph:arterial concentration gradients.

Glucose turnover was assessed from hyperglycaemic hyperinsulinaemic glucose clamps. Since studies done at hyperglycaemia can mask defects in insulinmediated glucose disposal because of the potentiating effects of glucose per se on $R_{d}[18]$, which is intact in Type I diabetes [30], all dogs were studied at matched hyperglycaemia. Somatostatin was given to suppress insulin secretion in animals with intact beta-cell function. Under these conditions, animals treated with alloxan showed a $55 \%$ reduction in supra-basal glucose uptake, indicating insulin resistance. This resistance was greater when one considers that lower $\mathrm{R}_{\mathrm{d}}$ in diabetic dogs existed despite higher arterial insulin, compared with control animals. Thus, wholebody sensitivity of insulin to stimulate $\mathrm{R}_{\mathrm{d}}\left(\mathrm{S}_{\mathrm{IP}(\mathrm{clamp})}=\right.$ $\Delta \mathrm{R}_{\mathrm{d}} / \Delta$ arterial insulin $\times$ glucose) was nearly $75 \%$ reduced in diabetic dogs (Table 2).

To examine the causes of insulin resistance, we considered that insulin's ability to stimulate glucose utilization by extrahepatic tissues was a function of interstitial insulin concentrations, plus the ability of the interstitial insulin signal to effect an increase in tissue glucose uptake. Movement of insulin from the plasma to interstitial fluid was estimated as the observed increment in lymph insulin for a given increment in arterial plasma insulin at steady state ( $\Delta$ lymph insulin: $\Delta$ plasma insulin). This gradient was similar for dogs treated with alloxan or with saline $(0.533 \pm 0.033$ vs $0.539 \pm 0.022)$, as were kinetics of lymph and plasma insulin during insulin infusion (Fig.4). Interstitial insulin being unchanged, whole body peripheral resistance must have resulted from a decrease in the ability of lymph insulin to stimulate $\mathrm{R}_{\mathrm{d}}$ (i.e. cellular insulin resistance). Indeed, this variable was reduced by $70 \%$ in dogs treated with alloxan (Table 2). This defect is similar to an approximate $80 \%$ reduction in target cell sensitivity $\left(\mathrm{R}_{\mathrm{d}} /\right.$ interstitial insulin) observed in obese Zucker rats using microdialysis [12]. Thus, whole body peripheral insulin 
resistance induced by alloxan is caused by defect(s) downstream of the endothelial barrier.

An additional candidate pathway implicated in the insulin resistance of Type I diabetes is diminished blood flow. It has been reported that during pharmacologic hyperinsulinaemia (1800-3000 pmol/l), blood flow was considerably reduced in diabetic patients compared with non-diabetic subjects, and could completely account for observed resistance [8]. When clamps were performed at more physiologic insulin levels $(600 \mathrm{pmol} / \mathrm{l})$, however, no difference in blood flow between Type I diabetic and non-diabetic subjects was observed whereas glucose extraction was reduced [31]. Because of the potential influence of inhalant anaesthesia on blood flow, our study was not designed to address directly the role of blood flow in the resistance of insulinopenic diabetes. Our observation of target cell insulin resistance, however, is consistent with reports of reduced glucose extraction measured at identical insulin concentrations [31]. Furthermore, insulin dynamics being similar in dogs treated with saline and with alloxan suggests that blood flow was not different between groups.

The interstitial insulin environment was described as the steady state concentration of lymph insulin, corrected for the corresponding plasma insulin, the values of which were presumed to result from exogenously injected insulin. Although C-peptide was not measured, endogenous insulin secretion was not expected to confound the estimation of this ratio. Dogs treated with alloxan have negligible insulin secretion (Figs. 2, 3). It is possible that non-diabetic dogs exhibit somatostatin breakthrough during hyperglycaemic clamps, even in the face of exogenous insulin infusion. We observed no such breakthrough during hyperglycaemia and basal insulin when a higher somatostatin dose $\left(1.6 \mu \mathrm{g} \cdot \mathrm{min}^{-1} \cdot \mathrm{kg}^{-1}\right)$ was used [18]. Even if such breakthrough occurred, we have shown the steady state lymph: plasma insulin ratio to be independent of insulin infusion rate within the physiologic insulin range [10]. Furthermore, lower insulin concentrations observed in control dogs compared with dogs treated with alloxan (Fig. 6) refutes beta-cell breakthrough of somatostatin inhibition.

Glucose uptake was measured from hyperglycaemic hyperinsulinaemic clamps, and thus represents the combined stimulatory effects of raised insulin and glucose. Since additional clamps were not carried out at euglycaemia, it is not possible to precisely measure the discrete effects of glucose and insulin on $R_{d}$. In a review of the metabolic effects of glucose per se, however [32], some of the authors of this report examined $\mathrm{R}_{\mathrm{d}}$ data from many laboratories in which clamps were done at different glucose and insulin concentrations. An equation was derived to predict $\mathrm{R}_{\mathrm{d}}$ from steady state known glucose and insulin concentrations [32]. Using data from clamps done with animals treated with saline in the present study, the equation predicts that raising plasma insulin by $474 \mathrm{pmol} / \mathrm{l}$ at a glucose of $16.7 \mathrm{mmol} / \mathrm{l}$, would result in $\mathrm{R}_{\mathrm{d}}=68.9 \mu \mathrm{mol} \cdot \mathrm{min}^{-1} \cdot \mathrm{kg}^{-1}$, remarkably similar to the observed value of $64.3 \mu \mathrm{mol} \cdot \mathrm{min}^{-1} \cdot \mathrm{kg}^{-1}$. In dogs treated with alloxan $(\Delta$ insulin $=678 \mathrm{pmol} / 1$, steady state glucose $=16.7 \mathrm{mmol} / \mathrm{l})$, the predicted $\mathrm{R}_{\mathrm{d}}$ was $77.8 \mu \mathrm{mol} \cdot \mathrm{min}^{-1} \cdot \mathrm{kg}^{-1}$, much higher than the $45.4 \mu \mathrm{mol} \cdot \mathrm{min}^{-1} \cdot \mathrm{kg}^{-1}$ observed. Although the extent to which this reduction reflects insulin or glucose resistance cannot be determined from these data, another study indicates that hyperglycaemia per se has the ability to stimulate $R_{d}$ in Type I diabetic subjects [30]. Overall, our results support the assertion that dogs treated with alloxan showed pronounced resistance to the actions of insulin (and glucose) to stimulate glucose utilization.

Interpreting insulin concentration gradients between plasma and interstitial fluid during hyperglycaemic clamps can be problematic, given reports that an acute increase of glucose can increase endothelial permeability to albumin in vitro [33]. We observed, however, no difference in either the lymph: plasma insulin gradient (0.533 vs 0.541$)$ or lymph insulin dynamics $\left(\mathrm{t}_{1 / 2}: 42.4\right.$ vs 40.7$)$ measured in normal dogs at hyperglycaemia (this study) or those tested at euglycaemia [27]. Any effects of acute hyperglycaemia could have been avoided by normalizing fasting hyperglycaemia by exogenous insulin infusion beforehand. Both plasma and lymph insulin, however, would need to have been monitored during this period to ensure re-establishment of a new stable steady state before the start of the clamp and the duration of this normalization period is not known. Prior infusion of insulin has also been shown to acutely increase insulin sensitivity [34], which could "mask" alloxan-induced resistance. Thus, we believe that doing clamps at matched hyperglycaemia was a reasonable approach to assessing plasma and interstitial insulin dynamics, and that the insulin concentration gradient between these compartments is independent of acute changes in glycaemia.

There are conflicting data about changes in insulin clearance in Type I diabetes or animal models of insulin deficiency. We observed a modest $25 \%$ decrease in insulin clearance in dogs treated with alloxan, compared with control animals treated with saline. This is in contrast with a study of dogs after pancreatectomy that reported no difference in hepatic extraction of portally infused insulin between diabetic and healthy animals studied at ambient glucose ( $40 \%$ vs $39 \%$ ) [35]. The reasons for the different results of the studies are not known. There is no evidence that anaesthesia (used in our study) affects insulin extraction [36], or should exert differential effects in diabetic compared with non-diabetic dogs. We observed no relation between clearance and fasting hyperglycaemia that could indicate that changes in clearance were associated with glycaemic control. 
In fact, in poorly controlled Type I diabetic subjects $\left(\mathrm{HbA}_{1 \mathrm{C}}=10.5\right)$ euglycaemic clamps with sequential insulin infusions (30 to $300 \mathrm{pmol} \cdot \mathrm{min}^{-1} \cdot \mathrm{kg}^{-1}$ ) resulted in clearance $28 \%$ higher than in non-diabetic control subjects [37]. One possible explanation for the decreased insulin clearance observed in our study is the presence of circulating insulin antibodies resulting from daily insulin injections. Insulin antibodies have been reported to protect the hormone from degradation in liver homogenates [38]. Our dogs, however, were studied less than 3 weeks after alloxan injection, whereas insulin antibodies are generally not detected before 2 months [17] and we saw no changes in plasma insulin kinetics which would have been expected with insulin antibodies.

It is possible that alterations in lymph insulin dynamics might have been observed if dogs were studied after a longer duration of diabetes. Diabetic microangiopathy is a chronic complication of Type I diabetic subjects and is believed to result from the toxic effects of chronic hyperglycaemia on endothelial cell function. Although degenerative changes are observed in the pancreatic islets within hours of alloxan injection [39], hypertrophy of the basement membrane may require more protracted exposure to the hyperglycaemic milieu. Increased vascular permeability to labelled albumin, however, was observed in multiple tissue beds after only 3 weeks in streptozotocin-injected rats [40]. The dogs treated with alloxan in this study also showed very variable fasting hyperglycaemia, ranging from normal $(5.6 \mathrm{mmol} / \mathrm{l})$ to $15.5 \mathrm{mmol} / \mathrm{l}$, although insulin release stimulated by glucose was abolished uniformly. Since changes in vascular permeability can be corrected by phlorizin alone [7], it appears likely that chronic hyperglycaemia rather than insulinopenia is necessary for development of these complications. It is possible that interstitial insulin dynamics may be altered under conditions of chronic hyperglycaemia, as in dogs after pancreatectomy.

Finally, we observed a small but consistent $20 \%$ decline in glucose tolerance over 3 weeks in dogs treated with saline, caused primarily by a comparable $23 \%$ decline in acute insulin response to glucose injection (Fig. 2). This result was unexpected and may result from changes in diet or activity or both from the breeding facility to the university vivarium. Nonetheless, metabolic dysfunction, although impaired over the 3 week interval, was mild compared with that observed in dogs treated with alloxan. Three weeks after alloxan had been given, dogs showed profound glucose intolerance $(68 \pm 7 \%$ decline from the time before injection), caused by a $92 \pm 4 \%$ drop in the acute insulin response. Abnormalities in glucose turnover in animals treated with alloxan were also evident from the glucose clamp, although animals did not serve as their own control animals in this protocol. Thus, we think that alloxan in- duced metabolic defects more severe then changes observed in animals treated with saline over the 3 week study period. Whether time-dependent changes in insulin transport may occur remains to be determined.

In conclusion, we observed a pronounced degree of glucose intolerance in dogs treated with alloxan because of the elimination of the beta-cell response to glucose. Glucose clamps showed that these dogs developed profound whole body insulin resistance. There was, however, no alteration in the lymph: arterial insulin gradient after alloxan, nor any change in dynamics of lymph insulin during infusion. These results indicate that alloxan induced resistance downstream of the capillary endothelial barrier at the level of insulin-sensitive tissues. The possibility of changes in insulin transport after longer duration or greater severity of diabetes would require further investigation.

Acknowledgements. The authors express their gratitude to Donna Moore for her surgical expertise and to Lena Minassian for carrying out assays. This work was supported by grants from the National Institutes of Health to Marilyn Ader (AG00544), Richard N. Bergman (DK29867, DK29867 Minority Supplement, and DK 27619) and Joyce M.Richey (AG00093).

\section{References}

1. DeFronzo RA, Hendler R, Simonson D (1982) Insulin resistance is a prominent feature of insulin-dependent diabetes. Diabetes 31: 795-801

2. Yki-Jarvinen H, Sahlin K, Ren JM, Koivisto VA (1990) Localization of rate-limiting defect for glucose diposal in skeletal muscle of insulin-resistant type I diabetic patients. Diabetes 39: 157-167

3. Caruso G, Proietto J, Calenti A, Alford F (1983) Insulin resistance in alloxan-diabetic dogs: evidence for reversal following insulin therapy. Diabetologia 5: 273-279

4. Reaven GM, Sageman WS, Swenson RS (1977) Development of insulin resistance in normal dogs following alloxan-induced insulin deficiency. Diabetologia 13: 459-462

5. Kahn BB (1996) Glucose transport: pivotal step in insulin action (Lilly Lecture). Diabetes 45: 1644-1654

6. Kahn BB, Charron MJ, Lodish HF, Cushman SW, Flier JS (1989) Differential regulation of two glucose transporters in adipose cells from diabetic and insulin treated diabetic rats. J Clin Invest 84: 404-411

7. Kahn BB, Shulman GI, DeFronzo RA, Cushman SW, Rossetti L (1991) Normalization of blood glucose in diabetic rats with phlorizin treatment reverses insulin resistant glucose transport in adipose cells without restoring glucose transporter gene expression. J Clin Invest 87: 561570

8. Baron AD, Laakso M, Brechtel G, Edelman SV (1991) Mechanism of insulin resistance in insulin-dependent diabetes mellitus: a major role for reduced skeletal muscle blood flow. J Clin Endocrinol Metab 73: 637-643

9. Yang YJ, Hope ID, Ader M, Bergman RN (1989) Insulin transport across capillaries is rate limiting for insulin action in dogs. J Clin Invest 84: 1620-1628 
10. Yang YJ, Hope ID, Ader M, Poulin RA, Bergman RN (1992) Dose response relationship between lymph insulin and glucose uptake reveals enhanced insulin sensitivity of peripheral tissues. Diabetes 41: 241-253

11. Castillo C, Bogardus C, Bergman R, Thuillez P, Lillioja S (1994) Interstitial insulin concentrations determine glucose uptake rates but not insulin resistance in lean and obese men. J Clin Invest 93: 10-16

12. Holmäng A, Mimura K, Bjorntorp P, Lonnroth P (1997) Interstitial muscle insulin and glucose levels in normal and insulin-resistant Zucker rats. Diabetes 46: 1799-1804

13. Bar RS (1992) Vascular endothelium and diabetes mellitus. In: Simionescu N, Simionescu M (eds) Endothelial Cell Dysfunctions. Plenum Press, New York, pp 363-381

14. Kwok CF, Goldstein BJ, Muller-Wieland D, Lee TS, Kahn CR, King GL (1989) Identification of persistent defects in insulin receptor structure and function in capillary endothelial cells from diabetic rats. J Clin Invest 83: 127-136

15. King GL, Johnson SM (1985) Receptor-mediated transport of insulin across endothelial cells. Science 227: 1583-1586

16. Steil GM, Ader M, Moore DM, Rebrin K, Bergman RN (1996) Transendothelial insulin transport is not saturable in vivo: no evidence for a receptor-mediated process. J Clin Invest 97: 1497-1503

17. Vranic M, Kawamori R, Pek S, Kovacevic N, Wrenshall GA (1976) The essentiality of insulin and the role of glucagon in regulating glucose utilization and production during strenuous exercise in dogs. J Clin Invest 57: 245-255

18. Ader M, Ni T-C, Bergman RN (1997) Glucose effectiveness assessed under dynamic and steady state conditions: comparability of uptake versus production components. J Clin Invest 99: 1187-1199

19. Finegood DT, Bergman RN, Vranic M (1987) Estimation of endogenous glucose production during hyperinsulinemiceuglycemic glucose clamps: comparison of unlabeled and labeled exogenous glucose infusates. Diabetes 36: 914-924

20. Bergman RN, Hope ID, Yang YJ et al. (1989) Assessment of insulin sensitivity in vivo: a critical review. Diabetes Metab Rev 5: 411-429

21. Andersen L, Dinesen B, Jorgensen PN, Poulsen F, Roder ME (1993) Enzyme immunoassay for intact human insulin in serum or plasma. Clin Chem 39: 578-582

22. Lee A, Ader M, Bray GA, Bergman RN (1992) Diurnal variation in glucose tolerance: cyclic suppression of insulin action and insulin secretion in normal weight, but not obese subjects. Diabetes 41: 750-759

23. Finegood DT, Bergman RN (1983) Optimal segments: a method for smoothing tracer data to calculate metabolic fluxes. Am J Physiol 244: E472-E479

24. Bradley DC, Steil GM, Bergman RN (1993) Quantitation of measurement error with Optimal Segments: basis for adaptive time course smoothing. Am J Physiol 264: E902E911

25. Bergman RN, Prager R, Volund A, Olefsky JM (1987) Equivalence of the insulin sensitivity index in man derived by the minimal model method and the euglycemic glucose clamp. J Clin Invest 79: 790-800

26. Ader M, Bergman RN (1987) Insulin sensitivity in the intact organism. In: Alberti KGMM, Home PD, Taylor R (eds) Bailliere's Clinics in Endocrinology and Metabolism. Bailliere Tindall, London, pp 879-910

27. Poulin RA, Steil GM, Moore DM, Ader M, Bergman RN (1994) Dynamics of glucose production and uptake are more closely related to insulin in hindlimb lymph than in thoracic duct lymph. Diabetes 43: 180-190

28. Bar RS, Hoak JC, Peacock ML (1978) Insulin receptors in human endothelial cells: identification and characterization. J Clin Endocrinol Metab 47: 699-702

29. Bryer-Ash M (1993) Altered distribution of insulin between intravascular and interstitial compartments in STZinduced diabetic rats. Diabetes 42: 1528-1535

30. Hother-Nielsen O, Vaag A, Skott P, Beck-Nielsen H (1993) Effect of hyperglycemia per se on glucose turnover rates in patients with insulin-dependent diabetes. Metabolism 42: 86-93

31. Makimattila S, Virkamaki A, Groop PH et al. (1996) Chronic hyperglycemia impairs endothelial function and insulin sensitivity via different mechanisms in insulin-dependent diabetes mellitus. Circulation 94: 1276-1282

32. Best JD, Kahn SE, Ader M, Watanabe RM, Ni T-C, Bergman RN (1996) Role of glucose effectiveness in the determination of glucose tolerance. Diabetes Care 19: 10181030

33. Yamashita T, Mimura K, Umeda F, Kobayashi K, Hashimoto T, Nawata H (1995) Increased transendothelial permeation of albumin by high glucose concentration. Metabolism 44: 739-744

34. Bergman RN, Finegood DT, Ader M (1985) Assessment of insulin sensitivity in vivo. Endocr Rev 6: 45-86

35. Ishida T, Chap Z, Chou J et al. (1984) Hepatic extraction of exogenous insulin in depancreatized conscious dogs. Am J Physiol 246: E369-E379

36. Ishida T, Lewis RM, Hartley CJ, Entman ML, Field JB (1983) Comparison of hepatic extraction of insulin and glucagon in conscious and anesthetized dogs. Endocrinology 112: 1098-1109

37. Nijs HGT, Radder JK, Frolich M, Krans HMJ (1990) In vivo relationship between insulin clearance and action in healthy subjects and IDDM patients. Diabetes 39: 333-339

38. Berson SA, Yalow RS (1959) Quantitative aspects of reaction between insulin and insulin-binding antibody. J Clin Invest 38: 1996-2016

39. Black HE, Rosenblum IY, Capen CC (1980) Chemically induced (streptozotocin-alloxan) diabetes mellitus in the dog. Am J Pathol 98: 295-310

40. Williamson JR, Chang K, Tilton RG et al. (1987) Increased vascular permeability in spontaneously diabetic $\mathrm{BB} / \mathrm{W}$ rats and in rats with mild versus severe streptozocin-induced diabetes: prevention by aldose reductase inhibitors and castration. Diabetes 36: 813-821 